ORIGINAL ARTICLE

\title{
Effects of Aerobics Versus Core Stability Exercises for the Management of Primary Dysmenorrhea
}

\author{
NIGHAT NASRULLAH KHAN ${ }^{1}$, SAIMA RIAZ ${ }^{2}$, REHAN RAMZAN KHAN ${ }^{3}$, HIRA MANNAN ${ }^{4}$, SOBIA GHAFOOR ${ }^{5}$, \\ HAYATULLAH KHALID ${ }^{6}$ \\ ${ }^{1}$ Physiotherapist, Allama Ehsan Hospital, Ghoray Shah, Lahore, Pakistan. \\ ${ }^{2}$ Assistant Professor, Riphah College of Rehabilitation and Allied Health Sciences, Riphah International University, Lahore, Pakistan. \\ 3Assistant Professor, Multan College of Physiotherapy, Multan Medical \& Dental College, Multan, Pakistan. \\ 4Lecturer, Government College University, Faisalabad, Pakistan. \\ 5Senior Physiotherapist, Ittefaq Hospital Trust, Lahore, Pakistan. \\ 6Assistant Professor, Multan College of Physiotherapy, Multan Medical \& Dental College, Multan, Pakistan. \\ Correspondence to: Dr. Saima Riaz, MS-OMPT, PhD*, Email: Saima.zahid@riphah.edu.pk, Cell: 0333-4349520
}

\begin{abstract}
Objective: To compare the effects of aerobics and core stability exercises for the management of primary dysmenorrhea.

Methodology: The study design was quasi-experimental, conducted in Yahya gym, Lahore, from February 2019 to July 2019. The sampling technique employed was non-probability convenient sampling with a sample size of 42 females within 18-30 years who had primary dysmenorrhea. The subjects were assigned into two groups. Group A was treated with aerobic exercises, while Group B was treated with core stability exercises with eight weeks workout plan and the results of three menstrual cycles were recorded. Stretching maneuvers were added as a standard treatment to both groups. Data were collected after 12 weeks and recorded for three menstrual cycles. Numeric Pain Rating Scale (NPRS) was used to measure pain intensity. Data were analyzed using IBM SPSS v.25.

Results: Mean age of group A vs. group B participants was $25.23 \pm 2.64$ vs. $21.38 \pm 3.41$ years respectively. Mean BMI score of group A participants was 21.38 \pm 2.14 while for group B participants mean BMI score was $21.65 \pm 1.99$ $\mathrm{Kg} / \mathrm{m}^{2}$.

Conclusion: This study concludes that both aerobic exercises and core stability exercises are effective to reduce the intensity of pain in primary dysmenorrhea. However aerobic exercises showed relatively better results in term of mean difference of NPRS score across both groups.

Keywords: Menstruation, Primary dysmenorrhea, Exercise, Pain.
\end{abstract}

\section{INTRODUCTION}

Menstruation is the recurrent cyclic flow of blood from the uterus through the vagina every month during the reproductive years. Menstruation occurs in the absence of pregnancy when the hormonal levels of progesterone and estrogen fall so that the buildup of the uterine lining is shed off. The median age at menarche remains 12-13 years. Menstruation is influenced by internal and external factors such as stress, fatigue, nutrition, organic diseases, hormonal disturbance and other environmental conditions. (1)

Dysmenorrhea is a supreme complication of menstruation prevalent among adolescent females. The term dysmenorrhea is coined from the Greek words meaning painful monthly flow (2). The condition is characterized by colicky, cramping pain in the supra-pubic region, which radiates to the lumbar region and groin area. Symptoms such as bloating, queasiness, diarrhea, headache, tiredness and vomiting coincide with dysmenorrhea. (3) Over half of all women of reproductive age experience painful menstruation; $10 \%$ of these women have severe dysmenorrhea, affecting 1 to 3 days each month. (4)

Primary dysmenorrhea is one of the most frequent gynecologic complaints among ovulating females. Definite absence of pelvic disease governs the diagnosis of primary dysmenorrhea. The prime causative agent for pain in primary dysmenorrhea is ischemia. Ischemia is linked with increased production of endometrial prostaglandins leading to abnormal uterine contractions. Circulation to uterine muscles is temporarily restricted, producing spasms in muscles and consequential cramping. $(5,6)$ Colicky pain in the lower abdomen and sacral region depicts primary dysmenorrhea. Pain is usually worse during the initial hours and subsides as bleeding commences. (7) The management of primary dysmenorrhea involves the usage of NSAID'S and may also be managed conservatively through bed rest, massage and distraction techniques. The physical therapy treatment regimen includes transcutaneous electrical nerve stimulation, shortwave diathermy, microwave diathermy, Pilates, aerobics and core stability exercises. (7) Exercises indirectly exert an analgesic effect by boosting the release of endorphins and thus provide significant relief from primary dysmenorrhea. (4) Regular exercise and physical activities have been suggested as helpful techniques for preventing and treating dysmenorrhea in the last 2-3 decades. (8) An increase in pain threshold is associated with an increase in endorphin hormone levels. $(8,9)$

Early dysmenorrhea and severe menstrual bleeding can be treated or prevented with regular and continuous aerobic exercise, according to a study by Mohammadi et al. aiming at investigating the effect of aerobic exercise on some of the menstrual symptoms of nonathletic students. (10) Aerobics are known to synchronize metabolic activities and sustain blood flow, which, in turn, enhance the functions of pelvic organs. Aerobic exercise helps in the liberation of endorphin hormones in the brain, raising the 
pain threshold by initializing prostaglandin inhibitors. (11, 12)

Although few clinical studies have been conducted on the effects of exercising on primary dysmenorrhea, no studies have compared the effects of aerobics and core stability exercises in primary dysmenorrhea. Thus, the present study aims to compare the effects of aerobics and core stability exercises on the prevention and treatment of dysmenorrhea.

\section{METHODOLOGY}

The design adopted for this study was a Quasi experimental. The study was conducted from February 2019 to July 2019 in Yahya Gym, Lahore after taking informed consent from members and the Gym management. The study was approved by the ethical research committee of Riphah College of rehabilitation sciences (RCRS). Through a non-probability convenient sampling technique, 42 females within the age group of 1830 years were included as a sample with a confirmed diagnosis of primary dysmenorrhea and were excluded if they were professional athletes, had psychological issues and took NSAIDs for pain relief or vitamin supplement during or before menstruation. The subjects were assigned into two groups. Group A was treated with aerobics while Group B with core stability exercises. Stretching maneuvers of lower trunk were added as a standard treatment to subjects of both groups. The study took 12 weeks and data was recorded for three menstrual cycles. Primary assessment and data collection took place during the initial four weeks following the menstrual cycle to assess the pain severity and complications of subjects in both groups with primary dysmenorrhea. Subsequently, after the subsequent two menstrual cycles, secondary assessments took place to evaluate and compare the effectiveness of aerobics and core stability exercises on primary dysmenorrhea.

The subjects assigned to Group A undergone an aerobic workout plan for eight weeks. Aerobics were performed three days per week with duration of forty five minutes. The workout started with warm up exercises for ten minutes. Free active movement of upper limb, lower limb, and upper body, cross toe to touch dynamic stretches such as lunges, achillies tendon and hamstrings stretching. The aerobic workout was done in the form of dance in groups. The duration was twenty five min. at an intensity of 70-80 percent of maximum heart rate, by Borg's scale RPE (rating of perceived exertion) every week. The intensity of the maximum heart rate was gradually increased from 60 to 80. The aerobic dance involved the following steps; single step touch, double step touch, marching, step touch front and back, grapevine, V step, leg curl, knee lift, forward walk, lunge side and back, reach out, jumping jacks and $L$ step. Cool down exercises included slow marching, slow $L$ step, V step, quadriceps and hamstring and TA stretching for ten minutes. Subjects were prohibited from aerobics during menstruation and data were recorded for two menstrual cycles.

The subjects assigned to Group B followed an organized plan of core stability exercises for eight weeks. Core stability exercises were performed for twenty minutes, three times a day and four days per week. The exercises were pelvic bridging, Planks, cat and camel and curl-ups.
Data were collected after 12 weeks and recorded for three menstrual cycles. Numeric Pain Rating Scale (NPRS) was used to measure pain intensity.

Quantitative variables were presented as mean and standard deviation. Repeated Measure ANOVA Test was used to show change of subjective as well as objective measurement over time. P-value of $\leq 0.05$ was considered as significant. Data were analyzed using IBM SPSS v.25.

\section{RESULTS}

Demographic characteristics of both groups is presented in table-I. Mean age of group A vs. group B participants was $25.23 \pm 2.64$ vs. $21.38 \pm 3.41$ years respectively. Mean BMI score of group A participants was $21.38 \pm 2.14$ while for group B participants mean BMl score was 21.65 \pm 1.99 $\mathrm{Kg} / \mathrm{m}^{2}$. Pair wise Comparison of NPRS and WaLIDD Scores within each group is presented in table-II. Pretreatment mean NPRS score for group A and group B was 7.85 vs. 7.23 respectively while post treatment 2 mean score of NPRS for group A and group B was 3.28 vs. 5.04 respectively.

Table-I: Demographic Characteristics of Both groups
\begin{tabular}{|l|l|l|}
\hline & $\begin{array}{l}\text { Group A } \\
\text { (Aerobics) }\end{array}$ & $\begin{array}{l}\text { Group B (Core } \\
\text { Stability) }\end{array}$ \\
\hline & Mean \pm SD & Mean \pm SD \\
\hline Age (Years) & $25.23 \pm 2.64$ & $21.38 \pm 3.41$ \\
\hline Weight (Kg) & $55.95 \pm 4.73$ & $54.14 \pm 4.73$ \\
\hline Height (Meters) & $1.62 \pm 0.06$ & $1.58 \pm 0.07$ \\
\hline BMI (Kg/m $\left.{ }^{2}\right)$ & $21.38 \pm 2.14$ & $21.65 \pm 1.99$ \\
\hline Menarche & $13.30 \pm 1.20$ & $13.10 \pm 1.30$ \\
\hline $\begin{array}{l}\text { Duration of Menstrual cycle } \\
\text { (days) }\end{array}$ & $25.60 \pm 3.30$ & $24.66 \pm 4.25$ \\
\hline Duration of Bleeding (days) & $5.60 \pm 1.65$ & $5.70 \pm 1.85$ \\
\hline
\end{tabular}

Table-II: Pair wise Comparison of NPRS Score within each group

\begin{tabular}{|l|l|l|}
\hline Pain intensity & $\begin{array}{l}\text { Group A } \\
\text { (Aerobics) }\end{array}$ & $\begin{array}{l}\text { Group B (Core } \\
\text { Stability) }\end{array}$ \\
\hline Pretreatment NPRS Score $\left(1^{\text {st }}\right.$ cycle $)$ & 7.85 & 7.23 \\
\hline $\begin{array}{l}\text { Post treatment NPRS 1 Score }\left(2^{\text {nd }}\right. \\
\text { cycle) }\end{array}$ & 5.71 & 6.61 \\
\hline $\begin{array}{l}\text { Post treatment NPRS 2 Score }\left(3^{\text {rd }}\right. \\
\text { cycle) }\end{array}$ & 3.28 & 5.04 \\
\hline
\end{tabular}

\begin{tabular}{|l|l|l|l|l|}
\hline & $\begin{array}{l}\text { Mean } \\
\text { difference }\end{array}$ & $\mathrm{p}$-value & $\begin{array}{l}\text { Mean } \\
\text { difference }\end{array}$ & $\mathrm{p}$-value \\
\hline $\begin{array}{l}\text { Pretreatment-Post } \\
\text { treatment 1 NPRS }\end{array}$ & 2.14 & $<0.001$ & 0.62 & $<0.001$ \\
\hline $\begin{array}{l}\text { Post treatment 1- } \\
\text { Post treatment 2 } \\
\text { NPRS }\end{array}$ & 2.43 & $<0.001$ & 1.57 & $<0.001$ \\
\hline $\begin{array}{l}\text { Post treatment 2- } \\
\text { Pretreatment } \\
\text { NPRS }\end{array}$ & 4.57 & $<0.001$ & 2.19 & $<0.001$ \\
\hline
\end{tabular}

\section{DISCUSSION}

Ovulation begins with the uterine lining being removed every month. The discarded debris is removed in the form of blood through the vagina. Expulsion of blood correlates with various symptoms such a pain, irritability, abdominal distension, nausea, headache and fatigue. Structural abnormalities, alongside other factors, influence the pattern and regularity of menstruation. Dysmenorrhea is the most common gynecologic complaint documented among females. Dysmenorrhea is categorized as primary if it does not coincide with any pelvic organ disease. Analgesics are 
the first line treatment option adopted by females suffering from primary dysmenorrhea. Several research studies support the positive correlation between exercises and reduced pain severity related to primary dysmenorrhea.

In his study, Israel et al. found that the intensity of dysmenorrhea symptoms decreased after 12 weeks of aerobic training. (13) Golub et al. reported in their study that primary dysmenorrhea complaints were less common among females engaged in sports and physical activity than non-exercisers. (14) The results of current study are supported by these studies.

Gamit et al. (2014) found in their study that stretching exercises effectively decrease the pain with primary dysmenorrhea in young females with a significant difference in Improving in VAS with $p<0.001$ post intervention. (15)

In 2012, another study done by Noor Bakhsh Mahvash reported the results of physical activity on primary dysmenorrhea in eight weeks. The current study follows the same time frame. The study outcomes in 2012 depict a positive association between physical activity and pain reduction in primary dysmenorrhea. (16)

The results have expressed that both aerobics and core stability exert a positive effect on primary dysmenorrhea but comparatively, aerobics has a more dominant effect. While comparing the results of both groups, the study reveals that aerobic dance showed a better reduction in pain and stress in primary dysmenorrhea when compared with core stability exercises. Thus the results coincide with the study done by Sutar et al. (17) on the effectiveness of aerobic exercises on primary dysmenorrhea.

\section{CONCLUSION}

This study concludes that both aerobic exercises and core stability exercises are effective to reduce the intensity of pain in primary dysmenorrhea. However aerobic exercises showed relatively better results in term of mean difference of NPRS score across both groups.

\section{REFERENCES}

1. Malhotra N, Malhotra J, Saxena R, Bora M. Jeffcoate's Principles of Gynaecology: Jaypee Brothers. Chennai, Tamilnadu: Medical Publishers Pvt Limited. 2008.

2. Algeo J. British or American English?: a handbook of word and grammar patterns: Cambridge University Press; 2006.

3. Unsal A, Ayranci U, Tozun M, Arslan G, Calik E. Prevalence of dysmenorrhea and its effect on quality of life among a group of female university students. Upsala journal of medical sciences. 2010;115(2):138-45
4. Vidya K. A study to assess the effectiveness of billig's exercise in reducing dysmenorrhea among adolescent girls at government higher secondary school kalapatti, Coimbatore: PPG College of Nursing, Coimbatore; 2014.

5. Shehata N, Arafa A, El Wahed H, Fahim AS, Hussein GK. Epidemiology of Dysmenor-rhea among university students in Egypt. Int J Womens Health Wellness. 2018;4(1):073.

6. Chantler I, Mitchell D, Fuller A. Diclofenac potassium attenuates dysmenorrhea and restores exercise performance in women with primary dysmenorrhea. The Journal of Pain. 2009;10(2):191-200.

7. Kaur S, Kaur P, Shanmugam S, Kang M. To compare the effect of stretching and core strengthening exercises on Primary Dysmenohrrea in Young females. IOSR Journal of Dental and Medical Sciences (IOSR-JDMS). 2014;1(13):2232.

8. Abbaspour Z, Rostami M, Najjar S. The effect of exercise on primary dysmenorrhea. Journal of Research in Health sciences. 2006;6(1):26-31.

9. Omidvar S, Bakouei F, Amiri FN, Begum K. Primary dysmenorrhea and menstrual symptoms in Indian female students: prevalence, impact and management. Global journal of health science. 2016;8(8):135.

10. Kohzad Mohammadi H, Pouretezad M, Shokri E, Tafazoli M, Dastjerdi M, Neghahban Siouki H. The effect of forearm kinesio taping on hand grip strength of healthy people. Journal of Kerman University of Medical Sciences. 2010;17(3):248-56.

11. Ponmathi $\mathrm{P}$, Kiranmayi $\mathrm{P}$, Sivakumar V. Comparison of aerobic versus stretching exercise programmes on pain and menstrual symptoms in subjects with primary dysmenorrhoea. J Women" s Health Care. 2016;5:327.

12. Tharani G, Dharshini E, Rajalaxmi V, Kamatchi K, Vaishnavi G. To compare the effects of stretching exercise versus aerobic dance in primary dysmenorrhea among collegiates. Drug Invention Today. 2018;10(Special Issue 1):2844-8.

13. Israel RG, Sutton M, O'Brien KF. Effects of aerobic training on primary dysmenorrhea symptomatology in college females. Journal of american college health. 1985;33(6):2414.

14. GOLUB LJ, Menduke H, LANG WR. Exercise and dysmenorrhea in young teenagers: a 3-year study. Obstetrics \& Gynecology. 1968;32(4):508-11.

15. Gamit KS, Sheth MS, Vyas NJ. The effect of stretching exercise on primary dysmenorrhea in adult girls. Int $\mathrm{J}$ Med Sci Public Health. 2014;3(5):549-51.

16. Mahvash N, Eidy A, Mehdi K, Zahra MT, Mani M, Shahla H. The effect of physical activity on primary dysmenorrhea of female university students. World Applied Sciences Journal. 2012;17(10):1246-52.

17. Sutar A, Paldhikar S, Shikalgar N, Ghodey S. Effect of aerobic exercises on primary dysmenorrhoea in college students. J Nurs Health Sci. 2016;5(5):20-4. 